\title{
A NEW WAY OF LEARNING
}

\author{
By Simon Boxall
}

SIX MONTHS AGO in this column, I reviewed how COVID-19 had impacted learning and teaching of oceanography and marine biology at the university level. At that stage, things were looking hopeful for a return to normality-I was even going out on the boat teaching small cohorts in a safe and socially distanced way. Six months on, little has changed. The UK government encouraged universities to return to face-toface teaching on May 17, 2021, the same week that most universities finish formal lectures and practical sessions to go into the assessment period-brilliant timing. Even postgraduate teaching ends as master's students go into dissertation mode. So, we now have a full year's cycle of experience to review how the teaching environment has changed and also to review some of the changes in the marine environment itself.

The pandemic has had some positive environmental impacts. There are reports from around the globe that water quality (or at least clarity) has been improving. With a dramatic cut in cruise liner voyages, leisure boat use, and ferry travel, we have seen low levels of suspended particulate matter in most coastal regions. Four weeks ago, our students measured a Secchi disk depth of $3.2 \mathrm{~m}$ in Southampton Water. In my many years sampling the region, the most I have ever observed prior to the pandemic was $1.7 \mathrm{~m}$. This increase in the photic zone along with lower levels of sediment resettling has also led to a measurably improved and more diverse seabed environment. The fact that we were all flying less (if at all), and many are working from home, has also decreased carbon emissions, by up to $17 \%$ at the peak of the crisis, according to the World Meteorological Organization. However, the long-term trend is sadly still on the increase, albeit two-thirds of what would have been expected had this been a normal year.

I have done significant amounts of teaching online from home, with interludes of taking small groups of students out on the boat. In the past, teaching schedules were limited by timetabling issues-with clashes for either the professor or the student, but also issues around availability of lecture theaters of the correct capacity. In my study at home, I can accommodate a tutorial for four or a lecture for two hundred-online of course. The only other demand on my study space is from my dog, and she just sits at my feet, making occasional guest appearances mid lecture. I asked one group of students what they would like more of in their lectures, and they said, "the dog!"

As with many lecturers in marine science, I love to perform on stage and see the live audience as part of the funperhaps we are all extroverts at heart. In the new regime, I have avoided the prerecorded lecture and still deliver live online using a variety of platforms. No one platform seems ideal, and I vary them depending on what I am doing and how they seem to develop week to week. I still get the buzz of the live lecture and have noted one big advantage-students ask far more (sensible) questions. In the lecture theater, there is always a small selection of students who will have their hands up on a regular basis, but the majority are nervous to do so. With the many platforms we use, students can put their hands up and ask questions via their microphones, but many will do so in the typed chat. Anyone who is really nervous can do so in a private message that only I see. In the early days I felt this was an intrusion in the flow of my delivery, but actually it turns a lecture into far more of an interactive experience for both teacher and student alike, even if it does test my multitasking capabilities. Students can see and hear the presentation clearly rather than as some distant blur from the back of the lecture theater. They can have their coffee and sandwich while listening, frowned upon in many university lecture theaters, and-a "win" for the average student - they can arrive at a 0900 lecture without having to have showered, breakfasted, and caught the bus.

The counter to all of this remote learning is the lack of face-to-face contact. There are still things that work best that way. Although the lecture experience does not have to be face-to-face, it is a must for boat and laboratory sessions. The move to small groups of seven or eight compared with pre-COVID groups of over 20 on the boat, and 20 in a lab rather than 60 , provides a far better face-to-face experience than we have ever delivered before. It is intensive for us at the teaching end, running a session maybe 15 times rather than five. You do find yourself forgetting what you have and haven't said by the time you get to session number 10 , but I have found I have gotten to know our students better in this new regime, and they are more involved in the practical work. There are, after all, only so many things each individual can do on a boat in a 
group of 24 over a four-hour period.

With the potential for a return to normal in the fall of 2021 (note the caution there, after past over-optimism), there is a "demand" that we return to traditional lectures, traditional exams, and traditional practical sessions (whatever they may be). This demand is coming in part from governments, but mainly from the media, driven by a few student groups. Whether these groups are mainly in the humanities and have had no direct contact with their academic staffs for nearly 18 months now, or are looking for reduced fees in the future, is hard to tell. As formal teaching for this academic year came to a close last week., I (virtually) sat down with my course groups covering three years of oceanography along with marine biology students to see what their thoughts were. Most actually like what we have come to call blended delivery. They really appreciate the face-to-face teaching on the boat and in labs, and many like a component of online delivery, particularly for the more traditional lectures. What they do miss from lectures is the social contact with their peer group, and as much can be said when it comes to the academic staff-I do miss those corridor chats. Nonetheless, in the future, many of my colleagues are looking to work from home more than they have in the past. We get more done, if only because we save a couple of hours of commuting each day, and online meetings tend to be more focused. You can also catch up on those emails in meetings where you are expected to attend but have limited input... or so I have heard.

One problem with this positive view of how well things are going is that we are not only missing those corridor chats with our colleagues but also those chats with colleagues from other institutions around the globe. The benefit of conferences being run online is that you no longer need to find the budget for the travel and hotels from those ever-stretched faculty finances. It also reduces our carbon footprint, which as environmental scientists we should be doing. However, the new science ideas and collaborations, so often born out of informal chats in the evening over a meal or a drink, are not coming along so often. This lack of opportunities to meet across institutions also means we're not sharing our educational experiences and developments either.

At the end of 2020, a COVID-19 Working Group led by Kate Hendry of the University of Bristol and supported by Jackie Pearson of the National Oceanography Centre Association of Marine Science National Capability Beneficiaries conducted a survey to assess the impact of COVID-19 on the wider UK marine science community. Of 193 respondents, just half of were university based. The full report, which can be found at https://naqbase.noc.ac.uk, identified those most strongly impacted by the pandemic as being (1) early career researchers, (2) women (who have often ended up juggling a career with home schooling of children), and (3) staff on fixed-term contracts. That covers many of my academic and research colleagues. In the early stages of the pandemic in the UK, $35 \%$ of marine fieldwork teaching was canceled or postponed along with over half of the face-to-face teaching. A large number of staff have found it hard to work from home, and many feel isolated without those corridor chats and interactions. Many (40\%) have seen their administrative workloads increase. Over half have had less time or opportunity to write new grant proposals, which is not surprising, given that much of the past year has been about major restructuring of courses as the main priority for delivering high-quality learning experiences for our students.

It would appear from the report that the current modi operandi, mid-COVID, are not sustainable in the long term for most institutions. However, there are some aspects that I think should be kept. I have sat in countless curriculum meetings in past years exploring how we might dramatically improve learning experiences for both undergraduate and postgraduate students, as well as making the learning more efficient. To start from a ground zero approach and rebuild better, and with experience, is a perfect solution that would never be implemented due to the time and effort it would take. Rather than the faculty forcing our approach, it has taken a pandemic. Many of my colleagues, who I do still meet online, on the boat, and in the lab, see a blended approach as the future. More materials will be placed online (both live and recorded) for the dissemination of information-the role the traditional in-class lecture has played. There will be smaller and more involved practical and boat sessions for the face-to-face component of a student's learning pathway. Fewer assessments will be carried out, often moving away from the traditional exam approach of decades past into more innovative activities, which may be more time-consuming to grade, but will provide better indications of students' abilities. Such suggestions would have been untenable two years ago, but we have found ourselves in a very different learning environment in 2021. Let's hope that 2022 brings us the opportunity for a new approach to learning, rather than continued firefighting in a pandemic. @

\section{AUTHOR}

Simon Boxall (srb2@noc.soton.ac.uk) is Associate Professor, Ocean and Earth Science, University of Southampton, National Oceanography Centre, Southampton, UK. 